Case Report

\title{
Small cell neuroendocrine carcinoma coexisting with adenocarcinoma of the uterine cervix - a rare entity
}

\author{
Mukta Meel ${ }^{1}$, Arpita Jindal ${ }^{1}$, Mukesh Kumar ${ }^{1}$, Alka Mittal $^{1}$ \\ ${ }^{\prime}$ Department of Pathology, SMS Medical College, Jaipur, India
}

\section{Keywords:}

Carcinoma, Cervix Immunohistochemistry; Neuriendocrine;

Tumor;

\section{ABSTRACT}

Squamous cell carcinoma and adenocarcinoma are the most common histological types of cervical cancer. The co-existence of two histological types is rare. Here we report a case of a 65 -year-old woman with a complaint of postmenopausal bleeding and a history of foul-smelling discharge per vagina for 8 months. On examination cervix flared up with growth, bled on touch, parametrium was involved and adherent anteriorly with bladder \& posteriorly with the rectum. Cervical biopsy revealed small cell carcinoma coexisting with Adenocarcinoma. Later it was confirmed by immunohistochemistry.

\section{Correspondence:}

Dr. Mukta Meel, MD

Department of Pathology,

SMS Medical College, Jaipur, India

Email:drmuktab@yahoo.com
Received : May $3^{\text {rd }} 2020$; Accepted : September $26^{\text {th }} 2020$

Citation: Meel M, Jindal A, Kumar M, Mittal A. Small cell neuroendocrine carcinoma coexisting with adenocarcinoma of the uterine cervix - a rare entity. J Pathol Nep 2020;10:1783-5. DOI 10.3126/jpn.v10i2.28736

Copyright: This is an open-access article distributed under the terms of the Creative Commons Attribution 4.0 International License, which permits unrestricted use, distribution, and reproduction in any medium, provided the original author and source are credited.

\section{INTRODUCTION}

Cervical cancer is the second most common cancer among women, the third most common cause of cancer-related death, and the most common cause of mortality from gynecologic malignancy worldwide. ${ }^{1} \quad$ The vast majority of cervical cancers are squamous cell carcinomas (SCC), which comprises $80 \%$ to $85 \%$, while $15 \%$ to $20 \%$ are from adenocarcinoma (ADC). ${ }^{2}$ Invasive tumours of unspecified morphology constitute the remaining 5-10\%.[3] The simultaneous occurrence of different histological types of cervical cancer has been rarely documented. The objective of this article is to be aware of rare cases of composite tumour of the cervix because of treatment, outcome, and prognosis of composite tumour in an early-stage disease in the light of recent literature.

\section{CASE REPORT}

A 65 years - old female patient complained of postmenopausal bleeding and a history of foul-smelling discharge per vagina for 8 months. She had her first 


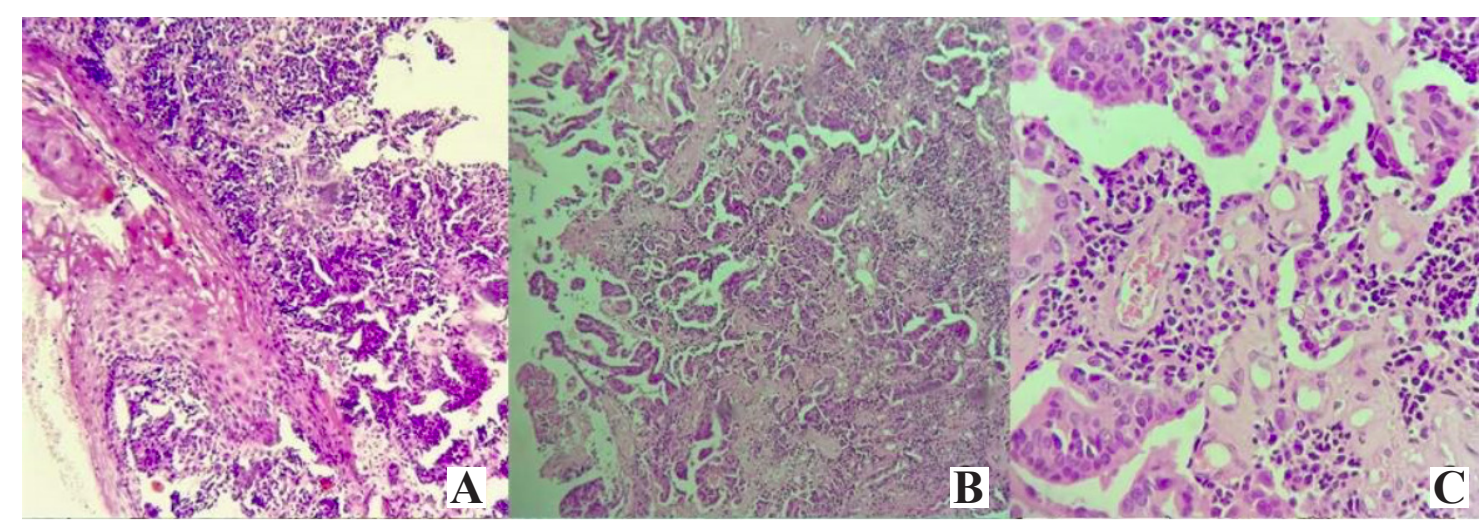

Figure 1: A) Small round tumour cells present just below the stratified squamous epithelium of cervix (HE stain, $X 40)$. B) small round neoplastic cells arranged intermixed with tumour cells arranged in a glandular pattern (HE stain, X40) and C) Perivascular rosette like arrangement of tumour cells (HE stain, X400)

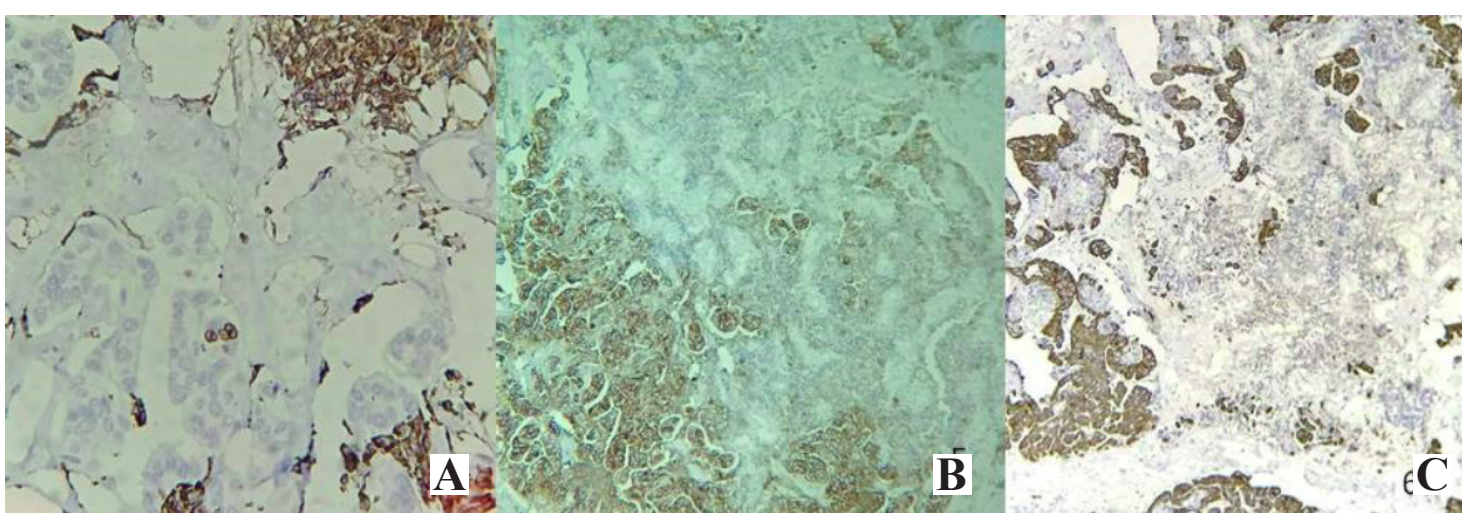

Figure 2: A) Granular cytoplasmic immunoreactivity of Synaptophysin in small round cells only (X100). B) Strong cytoplasmic immunoreactivity of CEA in glandular component only (X100) and C) Cytoplasmic immunoreactivity of PanCK in glandular component only (X100)

coitus at the age of 19 years to a single lifetime sexual partner. She had a history of OCP use for 20 years. On examination, the cervix flared up with a growth of about $5 \times 5 \mathrm{~cm}$ which bled on touch. Transvaginal ultrasonography showed a hypoechoic cervical mass measuring $6 \times 6 \times 5 \mathrm{~cm}$ within its stroma involving both parametria. Exploratory laparotomy was performed but due to adhesion of growth to bladder Total abdominal hysterectomy with salpingooophorectomy couldn't be performed. MRI showed an ill-defined mass lesion measuring $6.2 \times 5.5 \times 6.1 \mathrm{~cm}$, noted in lower uterine segment and cervix, with loss of fat planes to the posterior wall of bladder \& anterior wall of the rectum, likely to be Ca cervix. A cervical punch biopsy was performed. Cervix biopsy with HPE revealed squamous epithelium of cervix showing small round neoplastic cells arranged in nests and sheets intermixed with tumour cells arranged in a glandular pattern. Small round cells showed minimal cytoplasm and hyperchromatic nucleus, nuclear molding, isolated foci of cell debris, necrosis and lymphoplasmacytic infiltrate in the stroma. Welldifferentiated end cervical Adenocarcinoma was also noted adjacent to and admixed with sheets of small round cells. (fig.1A-1C) The sheets of small round neoplastic cells were diffusely positive for CD56, synaptophysin and negative for pancytokeratin and CK7 which is consistent with small cell neuroendocrine carcinoma. The glandular component was positive for pancytokeratin, CK7, and CEA and negative for vimentin, CD56, and synaptophysin. [fig. 2A-2C) Both components were negative for ER, $\mathrm{PR}$, and chromogranin. The morphology and immune profile favoured coexisting small cell neuroendocrine carcinoma and adenocarcinoma of the uterine cervix.

\section{DISCUSSION}

Etiological factors involved in cervical carcinogenesis are Human Papilloma Virus (HPV) infection, smoking, oral contraceptive pill use, and fertility. ${ }^{4}$ Oral contraceptive use is a well-established risk factor for cervical cancer. In our case patient had a history of OCP intake for 20 years. In line with the co-existence of two tumours and the different hypothesis on its occurrence, recent reports substantiated that HPV, particularly types 16 and 18 play a role in the etiology of cervical neuroendocrine (NEC) and mixed carcinomas. ${ }^{5}$ The involvement of the same organ by more than one tumour can be classified based on the manner of involvement by two tumours: A) Metastasis of one tumour in the substance of the other, the so-called cancer-to-cancer metastasis. B). Presence of two histologically different tumours in the same organ with a histologic admixture of the two tumours, called composite tumours. C) Presence of two histologically distinct tumors without histologic admixture 
of the two entities, termed as Collision Tumours. 6 In 1957, Melnick et al. First reported cases of coexistent SCC and ADC of the cervix; Dougherty and Cotten grouped them as combined or "mixed" carcinomas in 1964; and Abell, in 1973, classified them as a histologically distinct tumor. ${ }^{7}$ As clinical and imaging features of all histologic types of cervical cancer are similar, a preoperative diagnosis of a dual pathological condition is not possible and pathological identification of the dual components is the way to make a correct diagnosis. 8 NET co-existing with $\mathrm{ADC}$ and neuroendocrine differentiation in cervical carcinomas is unusual. So here we present a rare case of coexisting small cell neuroendocrine carcinoma $\&$ adenocarcinoma cervix. The exact cellular origin of neuroendocrine tumors of the cervix is still unresolved. Argyrophil and argentaffin cells are well described in the female genital tract. These neuroendocrine cells within the normal cervix have been suggested to give rise to neuroendocrine tumors. Adenocarcinoma components arise from a common precursor cell which is the multipotential sub columnar reserve cell found in the transformation zone. ${ }^{9}$

Recent reports and studies ventured on more sophisticated Immunohistochemical and molecular studies to verify diagnosis and histogenesis. Furthermore, in the diagnosis of such tumors, it is important to exclude rare tumors resulting from one cancer metastasizing to another or just a mere differentiation of a primary histologic type. ${ }^{5}$ Due to poorer prognosis of collision and composite tumors, chemotherapy with concurrent pelvic radiation therapy or systemic chemotherapy is administered in the adjuvant setting after appropriate diagnosis. This multimodal therapy may increase patient survival and possibly cure some patients with early clinical stage despite the tendency for early distant metastasis. Due to its rarity, there is still no standard concept on the treatment; a however collection of experience on these rare entities may soon deliver a standard protocol.

\section{CONCLUSIONS}

It is important to differentiate coexisting small cell neuroendocrine tumour \& adenocarcinoma from other malignant tumours of the uterine cervix. The diagnosis depends on a combination of light microscopy \& immunohistochemistry. Morphological features play an important role in making a diagnosis and imunohistochemistry studies offer additional useful assistance.Earlystagedisease isusuallyassociated withlymph node metastasis and the multimodality treatment approach includes surgery with adjuvant chemotherapy in this. In late-stage disease, primary chemotherapy and radiation is the treatment of choice followed by regular followup. The goal of this manuscript is to provide an insight into coexistence of neuroendocrine tumour of the cervix with adenocarcinoma. A thorough examination of the tumour is needed so that one doesn't miss the uncommon histologic type in wake of commonly encountered histological type.

\section{REFERENCES}

1. Billod JA, Domingo EJ. Collision tumors of the cervix - A Case Series: Its Clinical Significance in the Management of an Early Stage Disease. Acta Medica Philippina. 2018;52:565-72. Website

2. Anderson S, Hellstrom AC, Angstrom R, Stendahl U, Auer G, and Wallin KL. The clinicopathologic significance of laminin-5 c 2 chain expression in cervical squamous carcinoma and Adenocarcinoma. Int J Gynecol Cancer. 2005;15:1065-72. Crossref

3. Beckmann C, Ling F, Barzansky B, Herbert W, Laube D, Smith R. Obstetrics and Gynecology, 6th Edition. Philadelphia, Lippincott Williams \& Wilkins, 2010. pp. 375-87.

4. Domingo E, Dy Echo A. Epidemiology, prevention and treatment of cervical cancer in the Philippines. J Gynecol Oncol. 2009;20:11-6. Crossref

5. Ueda Y, Miyataki T, Okazawa M, et al. Clonality and HPV Infection Analysis of Concurrent Glandular and Squamous Lesions and Adeno squamous Carcinomas of the Uterine Cervix. Am J Clin Pathol. 2008;130:389-400. Crossref

6. Vyas M, Menon S. Collision tumor of kidney: A cases of renal cell carcinoma with metastasis of prostatic adenocarcinoma. Indian $\mathrm{J}$ Med Pediatr Oncol. 2013;34(1):21-3. Website

7. Kersemaekers, F, van de Vijver M, Fleuren G. Comparison of the Genetic Alterations in Two Epithelial Collision Tumors of the Uterine Cervix. A Report of Two Cases. Int J Gynecol Pathol. 2000;19:22530. Crossref

8. Brahmania M, Kanthan C and Kanthan R. Collision tumor of colon colonic adenocarcinoma and ovarian granulose cell tumor. World J Surg Oncol. 2007;5:118. Crossref

9. Yajima A, Fukuda M, Noda K, et al. Histopathological Findings Concerning the Morphogenesis of Mixed Carcinoma of the Uterine Cervix. Gynecol Oncol. 1984;18:157-64. $\underline{\text { Crossref }}$ 